\title{
Mössbauer Study of a Reduction Process in Iron Azaporphyrins*
}

\author{
T. KACZMARzyK ${ }^{a, \dagger}$, T. JACKOWSKI ${ }^{a}$, K. DzILIŃski ${ }^{a}$ AND L. KAniA ${ }^{b}$ \\ ${ }^{a}$ Institute of Physics, Czȩstochowa University of Technology \\ Armii Krajowej 19, 42-200 Częstochowa, Poland \\ ${ }^{b}$ Institute of Organic Chemistry, Polish Academy of Sciences \\ M. Kasprzaka 44/52, 01-224 Warsaw, Poland
}

\begin{abstract}
Electronic structure of the $\mathrm{Fe}(\mathrm{II})$ - and $\mathrm{Fe}(\mathrm{I})$-complexes of mono- and diazaporphyrins studied by the Mössbauer spectroscopy is considered in this paper. It was found that in the presence of tetrahydrofuran molecules, the electron configuration of $\mathrm{Fe}(\mathrm{II})$ ions in the studied complexes corresponds to the intermediate spin state $(S=1)$ and the complexation of tetrahydrofuran solvent does not change this state. Interaction of tetrahydrofuran solvent with $\mathrm{Fe}(\mathrm{I})$-azaporphyrins does not influence the electronic structure of $\mathrm{Fe}(\mathrm{I})$ ions coordinated to the porphyrin ligand, either. Electron configuration of $\mathrm{Fe}(\mathrm{I})$ ions in $\mathrm{Fe}(\mathrm{I})$-octaethylporphyrins and $\mathrm{Fe}(\mathrm{I})$-azaporphyrins is the same: $\left(d_{x y}\right)^{2}\left(d_{x z}, d_{y z}\right)^{4}\left(d_{z}^{2}\right)^{1}$. The $a z a$ substitution is reflected in the values of the Mössbauer parameters. Increasing number of nitrogen atoms at meso positions causes the increase in the quadrupole splittings within the range $1.49-2.24 \mathrm{~mm} / \mathrm{s}$ for the $\mathrm{Fe}(\mathrm{II})$ complexes and within the range $1.35-1.85 \mathrm{~mm} / \mathrm{s}$ for the Fe(I)-porphyrins. Values of the isomer shifts are decreased from 0.51 to $41 \mathrm{~mm} / \mathrm{s}$ for the same sequence of the $\mathrm{Fe}(\mathrm{II})$ complexes. For the $\mathrm{Fe}(\mathrm{I})$ reduced forms the isomer shifts are nearly constant and equal to about $0.37 \mathrm{~mm} / \mathrm{s}$. The Mössbauer results are discussed in association with EPR data for Fe(I)-porphyrins.
\end{abstract}

PACS numbers: 33.15.-e

\section{Introduction}

Metalloporphyrins are a class of macrocyclic tetrapyrrole complexes composed of four pyrrole rings joined by methine $(\mathrm{CH})$ bridges and coordinated to a metal ion localized near the center of a molecule. Iron porphyrins are known as model systems in investigations of important biological processes, for instance, the breathing of living organisms [1]. Prosthetic groups of heme proteins such as hemoglobin and myoglobin as well as some cytochromes, peroxidases and catalases consist of the porphyrin ring coordinated to an iron ion. Sufficient background information on the correlation between molecular structure of ligands coordinated to Fe-ions and their electronic structure provides a basis for discussion, on a molecular level, about the mechanism of complex biological processes which run with the participation of the heme proteins. Iron ions play a key role in biological processes which involve prosthetic groups of heme proteins. Iron porphyrins are also interesting objects for coordination chemistry because of variety of oxidation and spin

\footnotetext{
* Presented at the Polish Mössbauer Community Meeting, Koninki, Poland, June 8-11, 2008.

$\dagger$ corresponding author; e-mail: kcz@mim.pcz.czest.pl
}

states of the central Fe atom coordinated to the porphyrin ring and different axial ligands. The porphyrin macrocycle can be modified in many ways. One of them is the substitution of the $\mathrm{CH}$ groups at meso positions of the porphyrin ring by nitrogen atoms ( $a z a$ subsitution) which leads to azaporphyrins.

In this paper we wish to report how the $a z a$ substitution affects an electron configuration of $\mathrm{Fe}(\mathrm{II})$ and $\mathrm{Fe}(\mathrm{I})$ ions generated by the chemical reduction of $\mathrm{Fe}(\mathrm{III})-$ -porphyrins. The electronic structure of the reduction products is still controversial. Depending on a solvent used in the reduction process, kind of the reduction process (chemical or electrochemical), and the molecular structure of porphyrin ligands, Fe(II) ions can exist in all the possible spin states $(S=0, S=1$ and $S=2$ ) [2]. Results obtained from different experimental methods, even for the same Fe(II)-octaethylporphyrin complex, generated by reduction in the tetrahydrofuran (THF) solvent were interpreted ambiguously [3-5]. In the case of $\mathrm{Fe}(\mathrm{I})$-porphyrins their electronic structure is more uncertainly explained than the Fe(II) analogs. The $\left(d_{x y}\right)^{2}\left(d_{x z}, d_{y z}\right)^{3}\left(d_{z}^{2}\right)^{2}$ electron configuration of the $\mathrm{Fe}(\mathrm{I})$ ion was suggested in paper [2] while the authors of paper [6] proposed the $\left(d_{x y}\right)^{2}\left(d_{x z}, d_{y z}\right)^{4}\left(d_{z}^{2}\right)^{1}$ electron distribution in $d$-orbitals of this ion. On the basis of NMR and EPR measurements the low spin $(S=1 / 2)$ state was suggested [7] and on the basis of resonance Raman spec- 
troscopy - high spin $(S=3 / 2)$ state [8] or low spin with significant backbonding from the Fe(I) to the porphyrin ring [9]. In this paper we consider Fe(II)- and $\mathrm{F}(\mathrm{I})$-monoazaetioporphyrin [Fe(MAEP)] (Fig. 1a) and diazaoctaethylporphyrin [Fe(DAOEP)] (Fig. 1b) complexes with one or two $\mathrm{CH}$ methine bridges substituted by nitrogen atoms, respectively. Results are compared with unsubstituted $\mathrm{Fe}(\mathrm{II})$ and $\mathrm{Fe}(\mathrm{I})$-octaethylporphyrins $[\mathrm{Fe}(\mathrm{OEP})]$. All the above complexes were prepared and investigated in the same conditions.

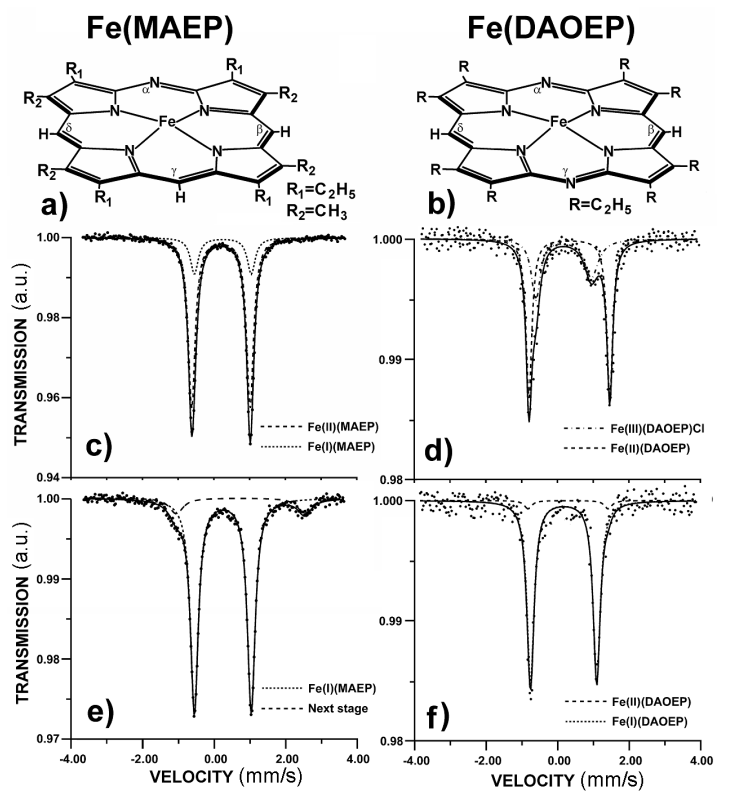

Fig. 1. Molecular structures (a), (b) and Mössbauer spectra (c)-(f) of Fe-azaporphyrins.

\section{Experimental procedures}

$\mathrm{Fe}(\mathrm{II})$ and $\mathrm{Fe}(\mathrm{I})$ porphyrin complexes, studied in this paper, were obtained by the chemical reduction from trivalent iron compounds which contained a chloride axial ligand in the fifth coordinate position. Fe(III)(MAEP)Cl and $\mathrm{Fe}(\mathrm{III})(\mathrm{DAOEP}) \mathrm{Cl}$ were synthesized according to the procedures described in $[10,11]$. $\mathrm{Fe}(\mathrm{III})(\mathrm{OEP}) \mathrm{Cl}$ complex was purchased from Aldrich Chemical Co. and was used as received. The reduction process was carried out by contact of THF solutions with sodium mirror. The course of the reduction was followed by electronic absorption spectra. THF solvent was carefully degassed by freeze-thaw cycles. The $\mathrm{Fe}(\mathrm{II})$ and $\mathrm{Fe}(\mathrm{I})$ reduction products are air sensitive and the reaction was run on a vacuum line. A special cuvette which contained a vessel where reduction reaction was carried out, cells for absorption and the Mössbauer spectra and a quartz tube for EPR spectra, allowed to run the reaction in anaerobic conditions. The samples for the Mössbauer measurements were prepared as layers obtained by the evaporation of THF solvent under vacuum at room temperature.
The spectra were recorded in the horizontal transmission geometry of a spectrometer and the samples had to be inserted into the instrument in vertical position. The geometric limitations caused a problem connected with destroying the layers during recording of the spectra. That is why the layers contained some amount of THF molecules which played a role of a binding material. The layers contained about $4 \times 10^{-4} \mathrm{~g} / \mathrm{cm}^{2}$ of ${ }^{57} \mathrm{Fe}$. The Mössbauer spectra were obtained with a ${ }^{57} \mathrm{Co}(\mathrm{Rh})$ source at room temperature. A metallic iron foil absorber was used to calibrate the velocity scale, and isomer shifts are given vs. metallic Fe. The parameters of the Mössbauer spectra were found by fitting the experimental spectra to Lorentzian lines using the NORMOS-90 programme [12].

\section{Results and discussion}

It is well established that when an electron is added to a trivalent $\mathrm{Fe}(\mathrm{III})$-porphyrin the chloride axial ligand is removed and a four-coordinate $\mathrm{Fe}(\mathrm{II})$-porphyrin is generated. When the next electron is added to the later divalent complex one can obtain $\mathrm{Fe}(\mathrm{I})$-porphyrin, or the $\pi$-anion $\mathrm{Fe}(\mathrm{II})$-(porphyrin) ${ }^{-}$or some combination of these two products. It is obvious that additional electrons joined to a molecule change its electronic structure. The Mössbauer spectroscopy, in association with numerical analysis of spectra, is a very effective tool for investigations of subtle effects of electronic structure in the case of chemical compounds or materials which contain Mössbauer-sensitive elements.

It was established earlier [13] that the successive nitrogen substitution of $\mathrm{CH}$ methine bridges leads to changes of spin states of the Fe(III)-porphyrins from the pure high-spin state $(S=5 / 2)$ for unsubstituted $\mathrm{Fe}(\mathrm{III})(\mathrm{OEP}) \mathrm{Cl}$, through the quantum-mechanically mixed spin states $(S=5 / 2+3 / 2)$ for the partly substituted $\mathrm{Fe}(\mathrm{III})(\mathrm{MAEP}) \mathrm{Cl}$ and $\mathrm{Fe}(\mathrm{III})(\mathrm{DAOEP}) \mathrm{Cl}$ azaporphyrins, to the pure intermediate spin state $(S=3 / 2)$ for the completely substituted Fe(III)-tetraazaoctaethylporphyrin complex. These electronic-structure modifications are reflected in the Mössbauer spectra by the increase in quadrupole splitting values and the decrease in the asymmetry of the spectroscopic doublets when the number of nitrogen atoms at the meso positions increases. The isomer shifts remain practically unchanged. It was suggested that the asymmetry of the Mössbauer spectra and the values of the quadrupole splitting can be used as parameters sensitive to the ratio of the components $S=5 / 2$ and $S=3 / 2$ in the quantum mechanically mixed spin states of trivalent iron porphyrins.

This paper can be considered as a next step in the investigation of Fe-azaporphyrins, dealing with low-valent Fe-compounds obtained in reduction process of the earlier studied trivalent corresponding complexes. The Mössbauer spectra of the Fe(II)- and Fe(I)-azaporphyrins are shown in Fig. 1. The parameters corresponding to these spectra are collected in Table. Each of these spectra consists of at least two components. This feature is connected with the fact that separation of a pure form of the 
$\mathrm{Fe}(\mathrm{II})$ or $\mathrm{Fe}(\mathrm{I})$ complex in the reduction process is practically imposible. In contrast to the $\mathrm{Fe}(\mathrm{III})$-porphyrin spectra, the doublets in the spectra of the Fe(II)- and
Fe(I)-complexes are symmetrical and show the nearly constant line width $\Gamma$.

TABLE

Mössbauer parameters of the Fe(II)- and Fe(I)-porphyrins at room temperature.

\begin{tabular}{c|c|c|c|c|c|c}
\hline \hline Mössbauer & \multicolumn{2}{|c|}{$\mathrm{Fe}(\mathrm{MAEP})$} & \multicolumn{2}{c|}{$\mathrm{Fe}(\mathrm{DAOEP})$} & \multicolumn{2}{c}{$\mathrm{Fe}(\mathrm{OEP})$} \\
\cline { 2 - 7 } parameter & $\mathrm{Fe}(\mathrm{II})$ & $\mathrm{Fe}(\mathrm{I})$ & $\mathrm{Fe}(\mathrm{II})$ & $\mathrm{Fe}(\mathrm{I})$ & $\mathrm{Fe}(\mathrm{II})$ & $\mathrm{Fe}(\mathrm{I})$ \\
& $S=1$ & $S=1 / 2$ & $S=1$ & $S=1 / 2$ & $S=1$ & $S=1 / 2$ \\
\hline$\delta[\mathrm{mm} / \mathrm{s}]$ & $0.414(2)$ & $0.367(2)$ & $0.408(6)$ & $0.385(4)$ & $0.539(2)$ & $0.363(2)$ \\
$\Delta E_{\mathrm{Q}}[\mathrm{mm} / \mathrm{s}]$ & $2.034(3)$ & $1.762(7)$ & $2.244(12)$ & $1.849(17)$ & $1.456(4)$ & $1.354(3)$ \\
$\Gamma[\mathrm{mm} / \mathrm{s}]$ & $0.245(4)$ & $0.223(5)$ & $0.260(18)$ & $0.234(14)$ & $0.211(8)$ & $0.215(6)$
\end{tabular}

\subsection{Iron(II) derivatives}

Fe(II)-porphyrins, generated in the first stage of the reduction process, belong to commonly occurring oxidation states in biological processes. A brief analysis of the Fe(II)-porphyrin data summarized in Table leads to the conclusion that the quadrupole splitting $\Delta E_{\mathrm{Q}}$ is more sensitive to the $a z a$ substitution than to the isomer shift $\delta$. A qualitative relationship between the $\Delta E_{\mathrm{Q}}$ values and a number of aza substituted methine bridges can be stated as follows: the larger number of the substituted $\mathrm{CH}$ groups, the higher value of the quadrupole splitting. The opposite relationship is observed for the isomer shifts. As it was mentioned in the experimental section of this paper, the Mössbauer samples, in the form of powder layers, contained molecules of THF solvent. During the heating at about $450 \mathrm{~K}$ under vacuum the $\mathrm{Fe}(\mathrm{II})(\mathrm{OEP}), \mathrm{Fe}(\mathrm{II})(\mathrm{MAEP})$ and $\mathrm{Fe}(\mathrm{II})(\mathrm{DAOEP})$ layers started to crumble and only small changes in the Mössbauer were observed in comparison with the spectra of the same samples before the heating. It suggests that the presence of THF molecules in the layers does not influence significantly an electronic configuration of the $\mathrm{Fe}(\mathrm{II})$ ions in the studied complexes. To check the above statement the similar experiment was done with $\mathrm{Fe}(\mathrm{II})$-tetraphenylporphyrin [Fe(II)(TPP)]. It was found earlier by the use of different experimental methods [14] that two THF molecules are bonded to the Fe(II)(TPP) complex as axial ligands at fifth and sixth coordinate positions and the $\mathrm{Fe}(\mathrm{II})$ ion is in the high-spin state $(S=2)$. As a result of the heating of the Fe(II)(TPP) layer which contained THF molecules we observed a Mössbauer spectrum composed of two components. The quadrupole splitting of one of them $\left(\Delta E_{\mathrm{Q}}=1.30 \mathrm{~mm} / \mathrm{s}\right)$ is close to that one for $\mathrm{Fe}(\mathrm{II})(\mathrm{OEP})$ and it is typical of the intermediate spin state $(S=1)$ [15]. The splitting of the another one $\left(\Delta E_{\mathrm{Q}}=2.31 \mathrm{~mm} / \mathrm{s}\right)$ is characteristic of the high-spin state $(S=2)[15]$. The quadrupole splittings of the $\mathrm{Fe}(\mathrm{II})$ (MAEP) and $\mathrm{Fe}(\mathrm{II})$ (DAOEP) compounds are significantly higher in comparison with the value for the $\mathrm{Fe}(\mathrm{II})(\mathrm{OEP})$ and they could be interpreted as corresponding to the $\mathrm{S}=2$ spin state, but the values of the isomer shifts (Table) correspond to $S=1$ [15]. Therefore, the increase in the $\Delta E_{\mathrm{Q}}$ values of the $\mathrm{Fe}(\mathrm{II})-$ -azaporphyrins are caused by the $a z a$ substitution.

Let us consider the quadrupole splitting values. It is well known that the value of the quadrupole splitting depends on interaction between a nuclear quadrupole moment and a nonzero electric field gradient (EFG) at the nucleus. Because nuclear quadrupole moment is constant for a given Mössbauer nuclide $\left({ }^{57} \mathrm{Fe}\right)$, changes in the quadrupole interaction energy, under constant experimental conditions, can only arise from variation of the EFG at the nucleus. The total EFG depends on three main factors: (i) valence electron contribution which originates from anisotropic electron distribution in the valence $d$-shell of the ${ }^{57} \mathrm{Fe}$ ion, (ii) lattice contribution from charges on distant atoms which surround the ${ }^{57} \mathrm{Fe}$ ion and (iii) lattice contribution from charge distribution in the covalent bonds. If we assume the same $\left[\left(d_{x y}\right)^{2}\left(d_{x z}, d_{y z}\right)^{2}\left(d_{z}^{2}\right)^{2}\right]$ electron configuration of $\mathrm{Fe}(\mathrm{II})$ ions, suggested on the basis of NMR measurements [2], for the $\mathrm{Fe}(\mathrm{OEP})$ and Fe-azaporphyrin complexes (which corresponds to the intermediate spin state $S=1$ ), the last two factors can cause increase in the quadrupole splitting as a result of the $a z a$ substitution. However, another electron distribution in $d$-orbitals of $\mathrm{Fe}$ (II) ions is also possible, for example $\left(d_{x y}\right)^{2}\left(d_{x z}, d_{y z}\right)^{3}\left(d_{z}^{2}\right)^{1}$, suggested on the basis resonance Raman spectroscopy [5]. It is difficult to say in this stage of the study which one of the above factors is dominant.

It follows from Table that the isomer shift is decreasing with the increase in the number of nitrogen atoms at the meso positions. Assuming that the population of $s$ atomic orbitals remains unchanged, some rearrangement effect resulting from changes in $3 d$ population of 
the $\mathrm{Fe}(\mathrm{II})$ ions can lead to a slight decrease in the isomer shifts. This suggestion is possible in the case of a significant back-bonding between the Fe(II) ion and porphyrin ligand. Because the $a z a$ substitution leads to the lowering of symmetry the porphyrin ring which can cause the change of $\mathrm{Fe}(\mathrm{II})$-ion vibrations, there is some possibility that the second order Doppler shift $\delta_{\text {SOD }}$ can also be altered. Temperature dependent measurements should be done to confirm or exclude the last statement.

Paramagnetic Fe(II)-porphyrins $(S=1$ and $S=2)$ are EPR silent because of the relatively large value of the zero-field splitting parameter $(D)[16]$.

\section{2. $\operatorname{Iron}(I)$ derivatives}

$\mathrm{Fe}(\mathrm{I})$-porphyrins, generated in the second stage of the reduction process, belong to complexes with unusual oxidation states. As intermediates they may be of importance for dioxygen activation in heme catabolism and for other biologically important processes. The Mössbauer spectra of the univalent Fe-azaporphyrins are shown in Fig. 1 and corresponding to them parameters are collected in Table. Like in the case of the $\mathrm{Fe}(\mathrm{II})$-azaporphyrins the quadrupole splitting values are increasing with the increase in the nitrogen number at the meso positions of the porphyrin ring, although within a more narrow range. Taking into account the relatively small changes of the isomer shifts in the $a z a$ substituted $\mathrm{Fe}(\mathrm{I})$-complexes and the values of the quadrupole splittings one can conclude that the $d$ -orbital population is the same for the three complexes and corresponds to the low-spin $(S=1 / 2)$ configuration rather $\left(d_{x y}\right)^{2}\left(d_{x z}, d_{y z}\right)^{4}\left(d_{z}^{2}\right)^{1}$ than $\left(d_{x y}\right)^{2}\left(d_{x z}, d_{y z}\right)^{3}\left(d_{z}^{2}\right)^{2}$ (the latter suggested on the basis of NMR study [2]). The former configuration confirm EPR data [17]. The EPR spectra of the $\mathrm{Fe}(\mathrm{I})$-azaporphyrins are similar in shape and parameters to the spectrum of $\mathrm{Fe}(\mathrm{I})(\mathrm{OEP})$. Characteristic feature of the EPR spectra of $\mathrm{Fe}(\mathrm{I})$-porphyrins in THF solution is a low-intensity hyperfine structure observed in frozen solution. The structure is stable to the moment when the solution is frozen. If the sample is thawed and then frozen again, the significant change of the relative intensities of the lines is observed. It suggests that this kind of the hyperfine splitting can be connected with an interaction of an unpaired electron with protons of THF molecules. The changeable form of this part of the EPR spectra indicates that the hyperfine-interaction lines correspond to some statistically average orientation of $\mathrm{THF}$ molecules with respect to the porphyrin ring.

\section{Conclusion}

Summing up, we can conclude that the electron configuration of $\mathrm{Fe}(\mathrm{II})$ ions in the presence of THF molecules in the studied complexes corresponds to the intermediate spin state $(S=1)$ and the complexation of THF solvent does not change this state. Like in the case of the
Fe(II)-complexes, interaction of THF solvent with Fe(I)porphyrins does not influence the electronic structure of $\mathrm{Fe}(\mathrm{I})$ ions coordinated to the porphyrin ligand. Electron configuration of $\mathrm{Fe}(\mathrm{I})$ ions is the same in the $\mathrm{Fe}(\mathrm{I})(\mathrm{OEP})$ and $\mathrm{Fe}(\mathrm{I})$-azaporphyrins, that is $\left(d_{x y}\right)^{2}\left(d_{x z}, d_{y z}\right)^{4}\left(d_{z}^{2}\right)^{1}$. Reduction process of Fe-porphyrins is rather complex and needs further systematic investigations, especially of highly-reduced species.

\section{Acknowledgments}

The authors would like to thank A.M. Shulga from the Institute of Molecular and Atomic Physics, Belarus Academy of Sciences, for synthesis of the $\mathrm{Fe}(\mathrm{III})(\mathrm{MAEP}) \mathrm{Cl}$ and $\mathrm{Fe}(\mathrm{III})(\mathrm{DAOEP}) \mathrm{Cl}$ complexes.

\section{References}

[1] K.M. Kadish, K.M. Smith, R. Guilard, The Porphyrin Handbook, Vol. 4, Academic Press, London 2000.

[2] G.N. Sinakov, A.M. Shulga, J. Mol. Struct. 295, 1 (1993).

[3] H. Goff, G.N. LaMar, C.A. Reed, J. Am. Chem. Soc. 99, 3641 (1978).

[4] D. Dolphin, R.J. Sams, J. Am. Chem. Soc. 98, 6970 (1976).

[5] T. Kitagawa, J. Teraoka, Chem. Phys. Lett. 63, 443 (1979).

[6] D.L. Hickman, A. Shirazi, H.M. Goff, Inorg. Chem. 24, 563 (1985).

[7] K. Yamaguchi, I. Morishima, Inorg. Chem. 31, 3216 (1992).

[8] J. Teraoka, S. Sashimoto, H. Sugimoto, M. Mori, T. Kitagawa, J. Am. Chem. Soc. 109, 180 (1987).

[9] C. De Silva, K. Czarnecki, M.D. Ryan, Inorg. Chim. Acta 287, 21 (1999).

[10] A.D. Adler, F.L. Longo, F. Kampas, J. Kim, Inorg. Nucl. Chem. 32, 2443 (1970).

[11] J. Engel, A. Gossauer, A.W. Johnson, J. Chem. Soc., Perkin Trans., 871 (1978).

[12] R.A. Brand, http://www.wissel-instruments.de/ produkte/software.html .

[13] T. Kaczmarzyk, T. Jackowski, K. Dziliński, G.N. Shulga, Nukleonika 49, S13 (2004).

[14] C.A. Reed, T. Mashico, W.R. Scheidt, K. Spartalian, G. Lang, J. Am. Chem. Soc. 102, 2302 (1980).

[15] P.G. Debrunner, in: Iron Porphyrins, Part III, Eds. A.B.P. Lever, H.B. Gray, VCH Publishers Inc., New York 1989, p. 128.

[16] S. Mitra, in: Iron Porphyrins, Part II, Eds. A.B.P. Lever, H.B. Gray, Addison-Wesley Publ. Co., London 1983, p. 31.

[17] K. Dziliński, T. Kaczmarzyk, T. Jackowski, G.N. Sinyakov, G.D. Egorova, Mol. Phys. Rep. 34, 65 (2001). 